\title{
Chirality in Microcystins
}

\author{
Thaiya Krishnamurthy \\ U.S. Army Chemical Research, Development and Engineering Center, Aberdeen Proving Ground, \\ Maryland, USA
}

\begin{abstract}
A new method has been developed to identify the isomers of amino acids by derivatization of the corresponding standards with 1-fluoro-2,4-dinitrophenyl-5-L-alanine amide (Marfey's reagent or FDAA) and analysis of the diastereomeric derivatives by a liquid chromatography-thermospray mass spectrometry technique. Quantification of the FDAA derivatives that originate from standards was possible by using $\mathrm{T}$-phenylalanine as the internal standard. The procedure was applied to determine the chiralities of the amino acids present in some previously uncharacterized blue-green algal peptides (microcystins). (J Am Soc Mass Spectrom 1994, 5, 724-730)
\end{abstract}

\section{$\mathrm{M}$} ost naturally occurring peptides and proteins are made up of L-amino acids. However, the cyclic hepatotoxic peptides (microcystins) isolated from blue-green algae (Cyanobacteria) are known to contain D-amino acids as well as L-amino acids [1-7]. All of these peptides contain four commonly occurring amino acids along with three unusual residues: Adda (3-amino-9-methoxy-2,6,8-trimethyl10-phenyldeca-4,6-dienoic acid), D-erythro- $\beta$-methylaspartic acid ( $\beta$-MeAsp), and $N$-methyldehydroalanine (Mdha) [1-7]. The stereochemistry of Adda in microcystins was assigned to be $2 S, 3 S, 85,95$ by chemical synthesis $[8,9]$. In all earlier known heptapeptides isolated from blue-green algae, in addition to these unusual invariant residues, two more invariant amino acids, D-Ala and D-Glu, were also present [1-3]. The remaining amino acids (Xaa, Yaa) were found to vary but were usually in $\mathbf{L}$ configuration in various combinations such as Leu \& Arg, Tyr \& Arg. Arg \& Met, or Arg \& Ala [1, 2].

However, the microcystins characterized more recently have various other amino acids in different combinations [3-7]. Earlier we reported certain blue-green algal peptides in which variant amino acids were found to be two Arg residues [3], a combination that had not been detected previously. We also characterized new blue-green algal peptides in which two amino acids, $\beta$-MeAsp and Mdha, which had been considered earlier as invariant residues, were replaced by Asp and Dha, respectively [3]. A detailed account of the microcystins characterized so far can be found elsewhere [3-7].

The general structure of these peptides was originally considered to be cyclo(D-Ala-L-Xaa-D- $\beta$-MeAsp-LYaa-Adda-D-Glu-Mdha) [1, 2, 4]. The general rules adopted for the nomenclature of microcystins were

Address reprint requests to Dr. Thaiya Krishnamurthy, U.S. Army Chemical Research, Development and Engineering Center, Aberdeen Proving Ground, MD 21010-5423. generated based on the variant $\mathrm{L}^{-}$and the demethylated D-amino acids present in the peptides [10] and were successfully applied for several newly characterized peptides that differed from the above proposed structure [4-7].

The chiralities of the amino acids present in some of the microcystins were assigned earlier based on the nuclear magnetic resonance (NMR) data of the peptides and gas chromatographic $(G C)$ separation of their hydrolysates over a Chirasil Val capillary column [1, 2]. During our investigations on previously uncharacterized hepatotoxic peptides that originate from various species of Cyanobacteria [3], we required a more selective, efficient, and sensitive procedure to establish the chiralities of the amino acids, including those that were not yet detected in any of the microcystins characterized earlier [3]. We pursued an approach that involved derivatization of amino acid isomers with an optically active derivatizing agent, Marfey's reagent (FDAA) [11], followed by liquid chromatographythermospray mass spectrometry analysis. The retention times of the derivatives on a reverse-phase $\mathrm{C}_{18}$ column as well as their corresponding molecular masses measured during the analysis enabled the identification of chiralities of the amino acids with one or more asymmetric center. The use of L-phenylalanine as the internal standard permitted quantification of the FDAA derivatives. The developed procedure was successfully applied to determine the chirality of the amino acids present in previously unknown blue-green algal peptides [3]. However, accurate measurement of the ratios of the isomers present in the hydrolysates of microcystins was not possible.

\section{Experimental}

The entire investigation was carried out with a Finnigan-MAT (San Jose, CA) TSQ 4600 tandem mass spectrometer, a Waters 600 multisolvent delivery system 
for separation of components, a Waters 510 solvent delivery system for postcolumn additions, and a Vestec (Houston, TX) thermospray ionization source.

The reverse-phase (Zorbax, Dupont) $\mathrm{C}_{18}$ column $(3.9 \mathrm{~mm}, 25 \mathrm{~cm}, 7 \mu \mathrm{m})$ was purchased from MAC-MOD Analytical Inc. (Chadds Ford, PA). The reagents and solvents used were either analytical or highperformance liquid chromatography (HPLC) grade. The HPLC grade solvents were purchased from Burdick and Jackson (Muskegon, MI). The hydrolysis tubes and 1-fluoro-2,4-dinitrophenyl-5-L-alanine amide (FDAA, Marfey's reagent) were purchased from Pierce Chemical Co. (Rockford, IL). Amino acid standards were purchased from Sigma Chemical Co. (St. Louis, $\mathrm{MO}$ ). The blue-green algal peptide standards and samples were supplied by Professor W. W. Carmichael of Wright State University, Dayton, $\mathrm{OH}$, under a contract with the U.S. Department of the Army.

\section{Hydrolysis of Peptides}

Peptide solution (1-5 nmol) was placed in the hydrolysis tube and freeze dried. The residue was treated with 6-M $\mathrm{HCl}(0.5-1.0 \mathrm{~mL})$ and degassed several times, and then the hydrolysis tube was filled with nitrogen and sealed. The solution was kept in a heating block maintained at $150{ }^{\circ} \mathrm{C}$ for $24 \mathrm{~h}$. The solution was cooled and freeze dried. The residue was kept in the freezer at $-20^{\circ} \mathrm{C}$ until use.

\section{Derivatization with Marfey's Reagent}

Amino acid standards or hydrolysates of peptides (200 pmol-50 nmol) in aqueous solution (50-100 $\mu \mathrm{L}$ ) were treated with a $1 \%$ solution $(w / v)$ of Marfey's reagent in acetone (60\% excess over the required amount) followed by $1.0-\mathrm{M}$ aqueous bicarbonate solution (10-50 $\mu \mathrm{L})$. The reaction mixture was heated at $40{ }^{\circ} \mathrm{C}$ in a heating block for $1 \mathrm{~h}$, cooled, and treated with 2-M $\mathrm{HCl}(20 \mu \mathrm{L})$. The $\mathrm{pH}$ of the resulting solution was adjusted to be 2 or less with an additional $2-\mathrm{M} \mathrm{HCl}$ if required. The solution was degassed and diluted with degassed water to adjust to a known final volume $(100-250 \mu \mathrm{L})$ prior to liquid chromatography-mass spectrometry (LC-MS) analysis.

\section{Liquid Chromatography-Mass Spectrometry Analysis of Diastereomeric Derivatives}

Standard or hydrolysatc derivative solution $(50 \mu \mathrm{L})$ was injected onto a $C_{18}$ column and eluted (1.5-2 $\mathrm{mL} / \mathrm{min}$ ) with $0.1 \%$ ammonium acetate in deionized water (solvent $\Lambda, \mathrm{pH}$ ) and acetonitrile (solvent $\mathrm{B}$ ) with a linear gradient of $0-50 \% \mathrm{~B}$ in $20 \mathrm{~min}$. The eluents were sprayed through the thermospray interface without postcolumn splitting. Postcolumn addition of $0.1 \%$ aqueous ammonium acetate $(\mathrm{pH} 5)$ at a rate of $0.3 \mathrm{~mL} / \mathrm{min}$ was made to the column effluent prior to introduction to the thermospray ionization source. The ionization was conducted at experimentally determined optimum aerosol $\left(240-250^{\circ} \mathrm{C}\right)$, block $\left(270^{\circ} \mathrm{C}\right.$ ), and tip $\left(256-242{ }^{\circ} \mathrm{C}\right)$ temperatures. The ions were analyzed either under selected ion monitoring mode $(0.87 \mathrm{~s} / \mathrm{cycle})$ or by scanning from $\mathrm{m} / \mathrm{z} 300$ to 600 every second.

\section{Results and Discussion}

Initially we pursued a simpler approach that involved separation of isomers of amino acids present in hydrolysates of microcystins over a chiral HPLC column and on-line analysis by a thermospray mass spectrometry technique. None of the commercially available chiral HPLC columns was found to be suited for this purpose. Hence, we followed a different approach that involved the introduction of an additional chiral center $[11,12]$ in each of the optical isomers of the amino acids to resolve them over a HPLC column prior to detection by thermospray mass spectrometry methods.

Individual D- and L-isomer standards for all amino acids except $\beta$-MeAsp were commercially available. Commercial $\beta$-MeAsp standard comprised a mixture of $D$ and $L$ isomers of erythro and threo forms. Initially derivatives (with Marfey's reagent) of $D$ and $L$ isomers of alanine, arginine, aspartic acid, glutamic acid, leucine, and $\beta$-methylaspartic acid were prepared to record the mass spectra. The derivatives that originate from $\mathrm{L}$ isomers are known to elute prior to the derivatives from $\mathrm{D}$ isomers on a reverse-phase $C_{18}$ column $[11,12]$. This phenomenon was verified by the LC-MS analysis of FDAA derivatives from individual isomers of Ala, Arg, Asp, Glu, and Leu. The eluted components were subjected to on-line thermospray ionization and their corresponding mass spectra were recorded by scanning the mass spectrometer from $\mathrm{m} / \mathrm{z} 300$ to 550.

The mass spectra of the FDAA derivatives of D-Glu and L-Arg are shown in Figures 1 and 2, respectively. The observed $[\mathrm{M}+\mathrm{H}]^{+}$ions confirm the expected reaction products that arose from the reaction of the fluoro group of the reagent with the amino group of

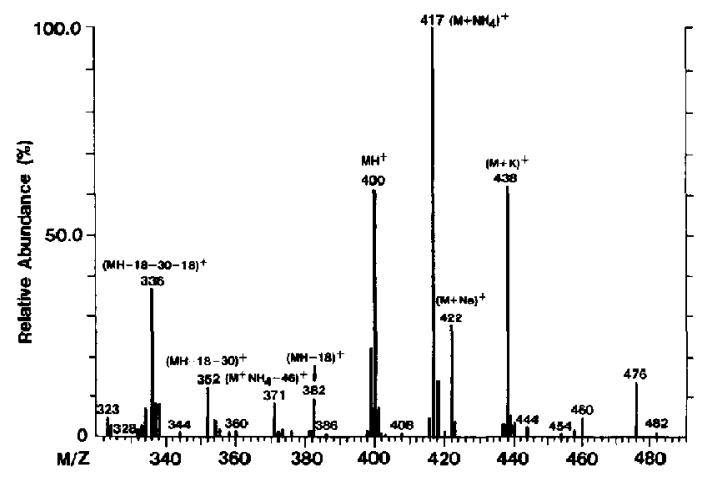

Figure 1. Thermospray ionization mass spectrum of D-glutamic acid. 


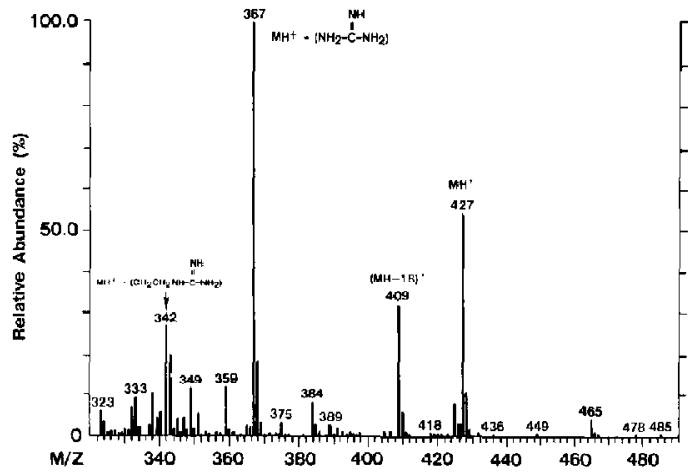

Figure 2. Thermospray ionization mass spectrum of L-arginine.

the amino acid and subsequent elimination of hydrofluoric acid [11]. Hence, the linkage should be at position 1 of the phenyl ring of the reagent. The mass spectrum of D-glutamic acid derivative (Figure 1) indicated that the ammonium adduct $\left(\left[\mathrm{M}+\mathrm{NH}_{4}\right]^{+}\right)$is more pronounced than the corresponding $[\mathrm{M}+\mathrm{H}]^{+}$. Adducts of acetic acid, sodium, and potassium also were observed. In the case of leucine, a methanol adduct also was detected.

Other ions resulted from the dissociation of $[\mathrm{M}+$ $\mathrm{H}]^{+}$or $\left[\mathrm{M}+\mathrm{NH}_{4}\right]^{+}$by the loss of $17\left(\mathrm{NH}_{3}\right), 18$ $\left(\mathrm{H}_{2} \mathrm{O}\right), 30(\mathrm{HCHO}), 32\left(\mathrm{CH}_{3} \mathrm{OH}\right)$, and $46(\mathrm{HCOOH}$ or $\mathrm{C}_{2} \mathrm{H}_{5} \mathrm{OH}$ ). In the case of the arginine derivative (Figure 2) the observed losses of 60 and 85 arose from side chain cleavages. In the case of alanine, only the loss of water was detected, which might well be due to the scanning of a limited mass-to-charge ratio range $(>300)$. In the isomers of glutamic acid and $\beta$ methylaspartic acid, a peak at $m / z 336$ possibly originated from consecutive losses of 18 and 32 from the $[\mathrm{M}+\mathrm{H}]^{+}$or by the loss of 17,18 , and 32 from its ammonium adduct. However, the relative abundance of $m / z 336$ was different between the isomers of Glu and $\beta$-MeAsp. The mass spectra of all diastereomeric derivatives that originate from the enantiomers examined appear to be similar, with slight variation of the relative abundance of their fragment ions. The ions selected for moniloring the amino acid derivalives in the LC-MS analysis are listed in Table 1.

The retention times of diastereomers of Glu and $\beta$-MeAsp, with the same molecular weights, were determined separately under carefully controlled liquid chromatography (LC) and selected ion monitoring mass spectrometry conditions $(m / z 417)$. $\beta$-MeAsp has two asymmetric centers that lead to four diastereomeric derivatives and Glu has one asymmetric carbon that leads to two derivatives. Mixtures that contain all six diastereomers of Glu and $\beta$-MeAsp were analyzed under identical conditions. The six diastereomers were well resolved and their chiralities could be established unambiguously from their corresponding retention times. Identical retention times were obtained upon repetition of the analysis. A multiple ion detection
Table 1. Thermospray LC-MS analysis of amino acid FDAA derivatives

\begin{tabular}{lcccr}
\hline Amino acid & $\begin{array}{c}\mathbf{M H}^{\prime} \\
(\mathrm{m} / \mathrm{z})\end{array}$ & $\begin{array}{c}{\left[\mathrm{M}+\mathrm{NH}_{4}\right]^{+}} \\
(\mathrm{m} / \mathrm{z})\end{array}$ & $\begin{array}{r}\text { Monitored } \\
\text { ion }(\mathrm{m} / \mathrm{z})\end{array}$ & $\begin{array}{c}\text { Detection } \\
\text { limit }^{\mathrm{a}}\end{array}$ \\
\hline \hline D-Ala & 342 & 359 & 359 & $400 \mathrm{pmol}$ \\
L-Ala & 342 & 359 & 359 & $400 \mathrm{pmol}$ \\
D-Arg & 427 & 444 & 427 & $20 \mathrm{pmol}$ \\
L-Arg & 427 & 444 & 427 & $20 \mathrm{pmol}$ \\
D-Asp & 386 & 403 & 403 & $400 \mathrm{pmol}$ \\
L-Asp & 386 & 403 & 403 & $50 \mathrm{pmol}$ \\
D-Glu & 400 & 417 & 417 & $400 \mathrm{pmol}$ \\
L-Glu & 400 & 417 & 417 & $200 \mathrm{pmol}$ \\
D-Leu & 384 & 401 & 401 & $3.0 \mathrm{nmol}$ \\
L-Leu & 384 & 401 & 401 & $1.5 \mathrm{nmol}$ \\
$\beta$-MeAsp & 400 & 417 & 417 & - \\
\hline
\end{tabular}

a Measured while monitoring a single ion for each of the derivatives sequentially by using a multiple ion detection experiment devised during the investigation; the signal-to-noise ratio was at least $6 / 1$.

Detection limit measurements were not possible due to the unavailability of individual standards.

(MID) experiment with the ions listed in Table 1 was performed to monitor the individual amino acid derivatives with increased sensitivity. The solution that contained all the derivatives $(50 \mu \mathrm{L})$ was separated by using a $\mathrm{C}_{18}$ column and analyzed under the above LC and MID conditions. All derivatives $(2.85 \mathrm{nmol})$ except less prominent diastereomers of $\beta$-MeAsp could be identified based on the observed selected ion traces (Figure 3). Mixlures that contained various amounts of the derivatives were analyzed under identical conditions to determine the detection limits, with signal-tonoise ratios of $6 / 1$, and the results obtained are also listed in Table 1 . The relative retention times for the

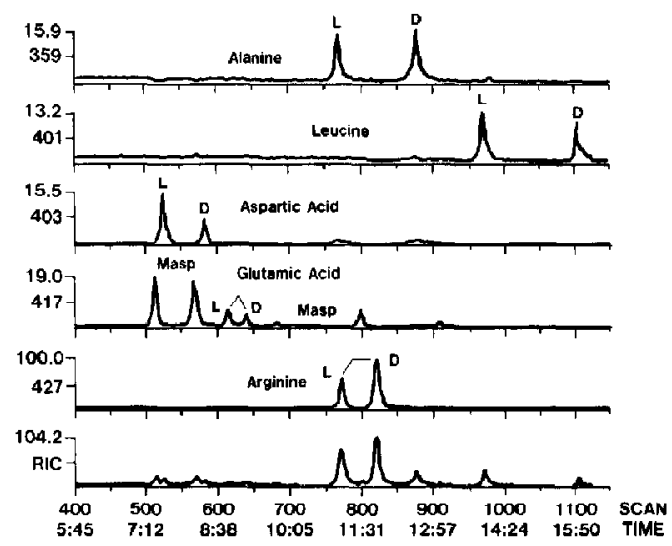

Figure 3. LC-MS analysis of FDAA derivatives of $D$ and $L$ isomers of amino acids. Repetitive scanning of selected ions for individual derivatives. Measurements were made from a mixture of equal amounts of amino acids. RIC is the reconstructed total ion current profile (sum of single extracted ion current profiles or mass chromatograms). The value indicated in the $y$ axis of each of the mass chromatograms is the mass-to-charge ratio of the monitored ion $\left[\mathrm{C}_{18}\right.$ HPLC column $(3.9 \mathrm{~mm}, 25 \mathrm{~cm}, 7 \mu \mathrm{m})$; solvent A, 0.1-M NH${ }_{4} \mathrm{OAC}_{;}$solvent $\mathrm{B}$, acetonitrile; $10-50 \%$ B in 5 $\min , 1.5 \mathrm{~mL} / \mathrm{min}]$. 
Table 2. Relative retention times of amino acid derivatives in the hydrolysates of microcystins ${ }^{3}$

\begin{tabular}{|c|c|c|c|c|c|c|c|c|c|c|c|}
\hline Sample & L-Ala & D-Ala & L-Leu & D-Leu & L-Asp & D-Asp & L-Glu & D-Glu & L-Arg & D-Arg & $\beta$-MeAsp ${ }^{b}$ \\
\hline$D$ and $L$ isomers & 0.87 & 1.00 & 1.11 & 1.27 & 0.59 & 0.65 & - & 0.72 & 0.89 & 0.94 & 0.65 \\
\hline Green Osc. & - & 1.00 & - & - & - & 0.66 & - & 0.72 & 0.88 & - & - \\
\hline Red Osc. & - & 1.00 & - & - & - & 0.66 & - & 0.72 & 0.89 & - & - \\
\hline Red Osc. & - & 1.00 & - & - & - & 0.65 & - & 0.72 & 0.89 & - & - \\
\hline $\mathrm{S} 23 \mathrm{G} 1^{\mathrm{f} . \mathrm{g}}$ & - & 1.00 & 1.11 & - & - & 0.66 & - & 0.72 & 0.88 & - & 0.65 \\
\hline S23G $1^{t, \mathrm{~h}}$ & - & 1.00 & 1.10 & - & 一 & 0.67 & - & 0.73 & 0.88 & - & 0.66 \\
\hline $7820^{g . i}$ & - & 1.00 & 1.12 & - & - & 0.65 & - & 0.73 & 0.88 & - & 0.65 \\
\hline Akerstox ${ }^{i}$ & - & 1.00 & 1.11 & - & - & - & - & 0.73 & 0.88 & - & 0.65 \\
\hline Monroe $e^{g / k}$ & - & 1.00 & 1.11 & - & - & 0.67 & - & 0.73 & 0.88 & - & 0.65 \\
\hline$D$ and $L$ isomers & 0.87 & 1.00 & 1.11 & 1.26 & 0.60 & 0.66 & - & 0.73 & 0.88 & 0.94 & 0.65 \\
\hline
\end{tabular}

${ }^{a}$ Retention time of D-Ala ranged from $12: 35$ to $12: 37$ min. The relative retention times of other amino acid isomers in each experiment were derived from the observed retention time for D-Ala-FDAA derivative during the same experiment.

${ }_{\beta} \beta$-methylaspartic acid (D-erythro).

Green Oscillatoria, Narway

Red Oscillatoria, Norway.

Crude sample.

${ }^{f}$ Microcystis aeruginosa, Canada.

${ }^{9}$ Occasionally in addition to microcystin-LR, its demethyl anglog also was isolated from the Microcystis aeruginosa samples indicated.

h Crude sample.

Microcystis aeruginosa, Scotland.

iMicrocystis aeruginosa, Norway.

kicrocystis aeruginosa, Monroe, Wisconsin.

standards with respect to that of D-Ala are listed in Table 2 and were found to be reproducible for experiments performed on different days. The retention times measured for D-Ala at various intervals were $12.35-12.37 \mathrm{~min}$.

Blue-green algal peptides that originate from Microcystis aeruginosa (collected at various geographical locations), red Oscillatoria, and green Oscillatoria were hydrolyzed with 6-M $\mathrm{HCl}$ under nitrogen at $150^{\circ} \mathrm{C}$ for $24 \mathrm{~h}$ and lyophilized. A reagent blank was also processed under identical conditions and the residue obtained was also derivatized with FDAA. Standard derivatives followed by a reagent blank were analyzed consecutively under the above LC-MS conditions. The sample derivatives also were analyzed under identical conditions. The reagent blanks were analyzed between each sample run to check any contamination or carryover from earlier analyses. In every instance, the blank runs were free from any interfering impurities. At the end of the last sample analysis, the standard analysis was repeated to examine any possible variance in the retention times. The observed results are listed in Table 2. Blue-green algal hydrolysate derivatives also were analyzed scanning from $\mathrm{m} / \mathrm{z} 300$ to 600 to confirm the observations made during the LC-MS analyses under MID mode. The identity of the amino acid in the sample was confirmed by comparison of the mass spectrum with the standards (Figure 4) and its chirality was confirmed from the relative retention time of its FDAA derivative. Peptides isolated from Microcystis and Oscillatoria also contain the same compositions and chiralities of amino acids as reported earlier for other microcystins [1-7]: All contain two variant amino acids in the L form, two invariant amino acids in the $D$ form, and either an aspartic acid or its $\beta$-methyl derivative in the $\mathrm{D}$ or D-erythro form, respectively (Figures 5-8).
During the full scan analysis of the derivatized microcystin hydrolysates, spectra with a base peak at $m / z 552$ were recorded (Figure 9), which could be explained by the elimination of methanol from [M + $\mathrm{H}^{+}$of the Adda-FDAA derivative. Neither the presence of the ammonium adduct nor $[\mathrm{M}+\mathrm{H}]^{+}$of the Adda-FDAA derivative were observed in the recorded
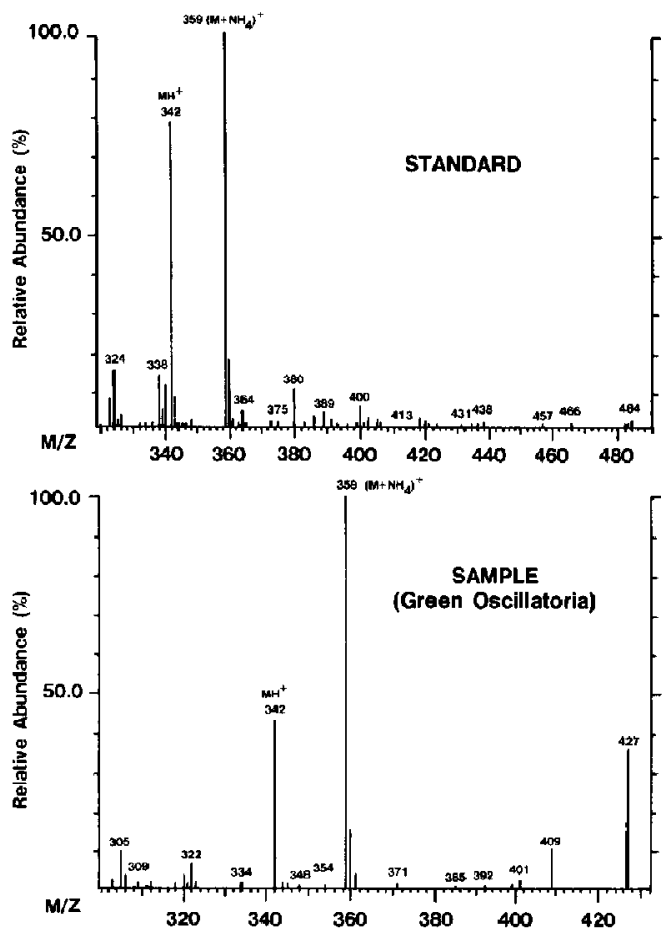

Figure 4. Mass spectra of standard D-alanine-FDAA derivative and sample (green Oscillatoria) hydrolysate-FDAA derivative. 


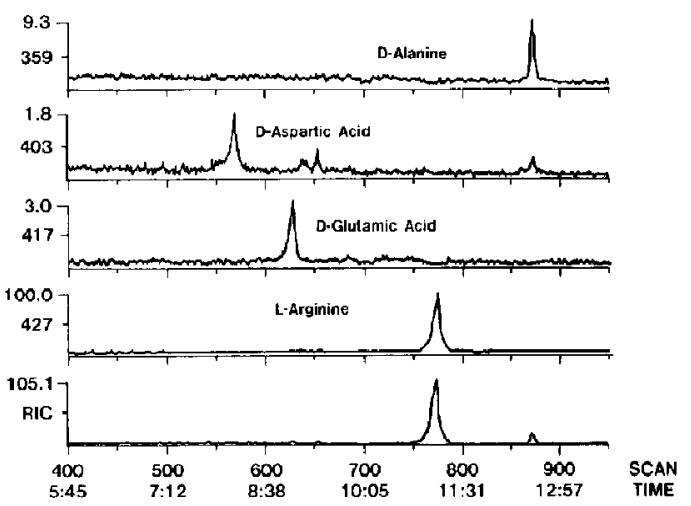

Figure 5. LC-MS analysis of red Oscillatoria hydrolysate-FDAA derivatives. Repetitive scanning of selected ions for individual derivatives. RIC is the reconstructed total ion current profile (sum of single extracted ion current profiles or mass chromatograms). The value indicated in the $y$ axis of each of the mass chromatograms is the mass-to-charge ratio of the monitored ion $\left[C_{18}\right.$ HPLC column $(3.9 \mathrm{~mm}, 25 \mathrm{~cm}, 7 \mu \mathrm{m})$; solvent $A, 0.1-\mathrm{M}$ $\mathrm{NH}_{4} \mathrm{OAC}$; solvent $\mathrm{B}$, acetonitrile; $10-50 \% \mathrm{~B}$ in $5 \mathrm{~min}, 1.5$ $\mathrm{mL} / \mathrm{min}]$

spectra. This corroborates the earlier report regarding the loss of methanol from Adda during the hydrolysis of microcystin or nodularin (a toxic pentapeptide that also contains Adda) [9].

We reported earlier the sequence of the toxic peptide isolated from green Oscillatoria algae to be cyclo(D-Ala-I-Arg-D-isoAsp-L-Arg-Adda-D-Glu-Dha) [3]. One of the peptides isolated from red Oscillatoria (1023 MW) was found to be cyclo(D-Ala-L-Arg-erythroD- $\beta$-MeAsp-L-Arg-Adda-D-Glu-Dha), based on an approach similar to that reported earlier [3].

Experiments also were conducted to determine quantitatively the chiralities and the ratios of the amino acids present in the blue-green algal peptides. L-Phenylalanine was selected as the internal standard based

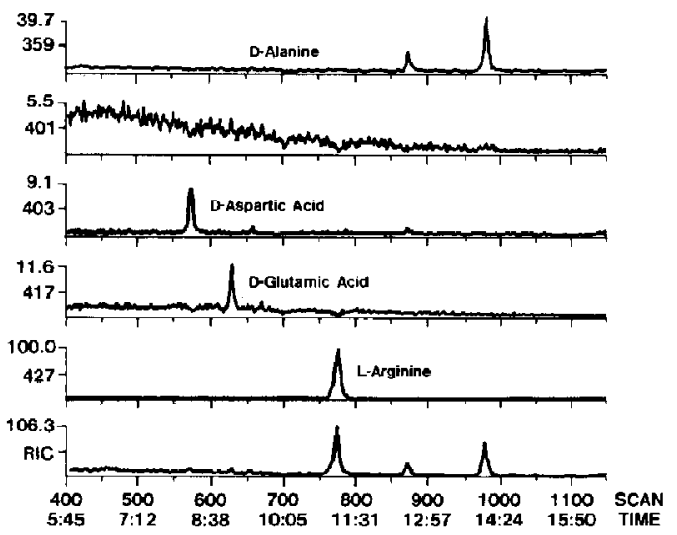

Figure 6. LC-MS analysis (selected ion monitoring) of green Oscillatoria hydrolysate-FDAA derivatives. Details as in Figure 5.

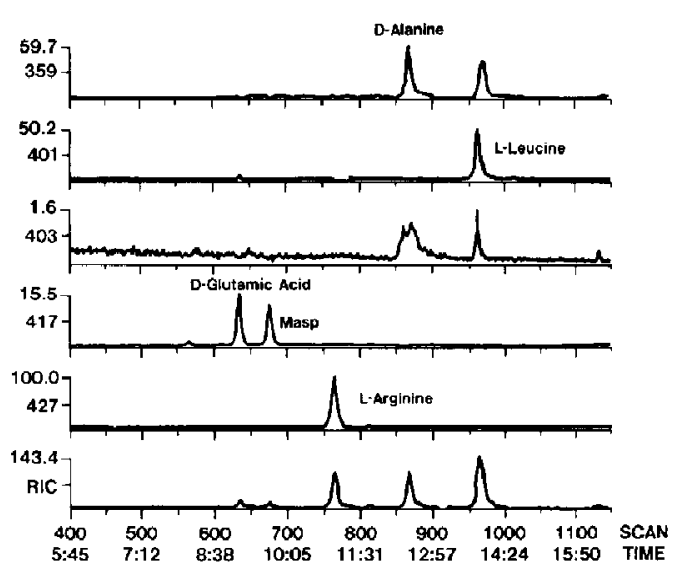

Figure 7. LC-MS analysis (selected ion monitoring) of Microcystis aeruginosa (Monroe, Wisconsin) hydrolysate-FDAA derivatives. Details as in Figure 5.

on its distinct retention time and modest cost in comparison with its corresponding $\mathrm{D}$ isomer or isotopically labeled molecule. Most importantly it was not detected in any of the investigated microcystins [3]. L-Phe has been observed to be one of the variant amino acids in microcystins [4, 5, 7], in which case L-Phe would not be a suitable internal standard to quantify the isomers present in those microcystins. In such cases, any other isomer of amino acids that is absent in the investigated microcystins and meets the requirements stated above would be an adequate internal standard. During our investigations, L-Phe was derivatized with FDAA reagent and subsequently analyzed under the LC-MS conditions discussed above. The corresponding mass spectrum $(m / z 300-550)$ indicated that the fragmentation pattern was similar to that observed for other amino acids. Ions resulting from the loss of $\mathrm{NH}_{3}$, acetic acid $(60), \mathrm{C}_{6} \mathrm{H}_{5}(77)$ from $[\mathrm{M}+\mathrm{H}]^{\dagger}$, and its corresponding ammonium adduct also were observed.

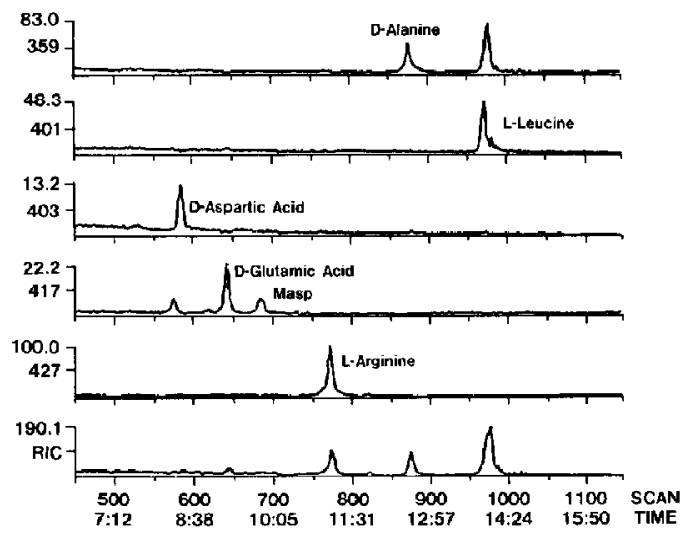

Figure 8. LC-MS analysis (selected ion monitoring) of Microcystis aeruginosa (Canada) hydrolysate-FDAA derivatives. Details as in Figure 5. 

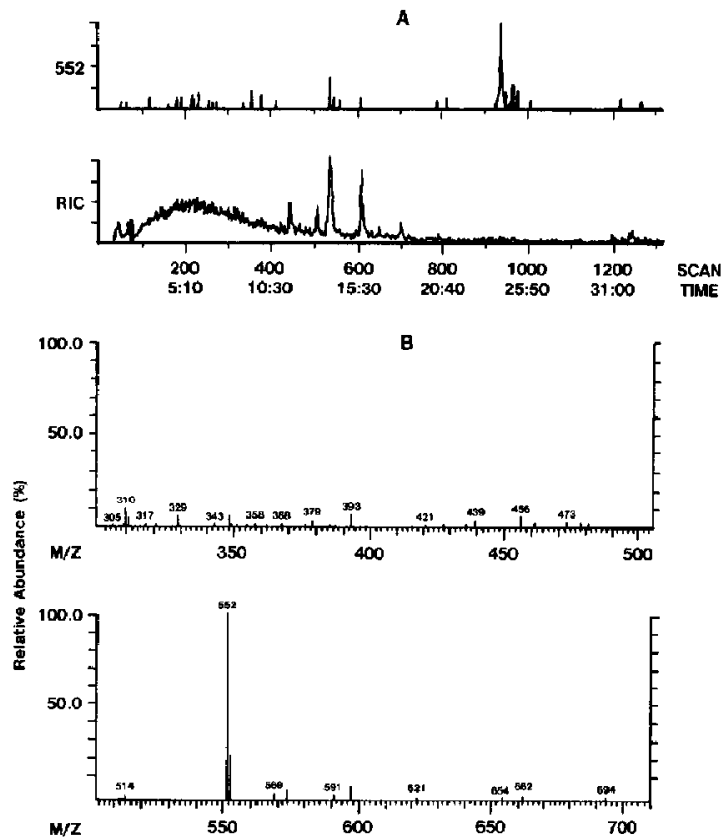

Figure 9. LC-MS analysis of Adda-FDAA derivative. (a) Mass chromatogram, $\mathrm{MH}^{+}-32$; (b) Mass spectrum.

The signal that corresponds to $\left[\mathrm{M}+\mathrm{NH}_{4}\right]^{+}$was greater compared to $[\mathrm{M}+\mathrm{H}]^{+}$in the recorded mass spectrum $(m / z 300-550)$, and it was also significantly higher in comparison with the observed sensitivity, under identical mass spectrometry conditions, for the most abundant ion of other amino acid derivatives. Hence, the less abundant $\mathrm{MH}^{+}$ion of L-phenylalanine was utilized during quantification.

Standard solutions with amounts ranging from 1.25 to $37.5 \mathrm{nmol}$ of analytes and $5 \mathrm{nmol}$ of internal stan- dard were analyzed. Relative amounts of individual amino acid derivatives along with their corresponding measured relative ion counts were fitted into a linear regression curve. The calculated regression constants and relative retention times are listed in Table 3 . Such correlation was not possible for any of the $\beta$-MeAsp isomers due to the unavailability of standards.

Similarly, derivatized hydrolysates from crude Microcystis aeruginosa samples that contained microcystin-LR were quantified by using the same internal standard. Each sample run was preceded by a blank analysis as before. The relative abundances of detected amino acids in the hydrolysates were determined from the calibration curves of the corresponding derivatized amino acid standards. The observed ratio for D-Ala, L-Arg, $\beta$-MeAsp, D-Glu, and L-Leu differed considerably from the expected ratio (for all amino acids) of 1 . However, a linear relationship between the analyzed amounts and observed ion counts was demonstrated earlier during the analysis of standard derivatives (Table 3). Hence, the discrepancy in the observed ratios only may be explained by the error introduced during hydrolysis and the effect of heat on the released amino acids. Optimization of the hydrolytic and experimental conditions might improve the quantification results.

During the quantification of one of the two Microcystis 7820 (Scotland) peptide samples, a smaller amount of D-Asp was observed along with $\beta$-MeAsp. Previous reports noted that in addition to microcystin$\mathrm{LR}$, its corresponding demethylated (D-Asp) analog was also isolated from Microcystis species found in Scotland, Canada, and Monroe, Wisconsin [3]. Hence, the presence of trace amounts of D-Asp, which originated from the demethylated analog, in one of the algal samples corroborated our earlier results [3].

The chiralities of the amino acids present in some of the microcystins were assigned earlier based on the NMR data of the peptides and GC separation of their

Table 3. Correlation of observed relative ion counts versus relative concentration of FDAA derivatives

\begin{tabular}{|c|c|c|c|c|c|}
\hline $\begin{array}{l}\text { Amino acid } \\
\text { derivative }\end{array}$ & $\begin{array}{c}\text { lon } \\
(m / z)\end{array}$ & $\mathrm{RRT}^{\mathrm{a}}$ & $\begin{array}{l}\text { Correlation } \\
\text { coefficient }^{b}\end{array}$ & Intercept & Slope \\
\hline L-Phe & 418 & 1.00 & - & - & - \\
\hline L-Ala & 342 & 0.80 & 0.9964 & -0.03 & $0.40 \pm 0.01$ \\
\hline D-Ala & 342 & 0.89 & 0.9972 & 0.00 & $0.77 \pm 0.02$ \\
\hline L-Arg & 427 & 0.80 & 0.9980 & -0.38 & $2.44 \pm 0.05$ \\
\hline L-Asp & 386 & 0.55 & 0.9993 & -0.05 & $0.41 \pm 0.01$ \\
\hline D-Asp & 386 & 0.57 & 0.9942 & -0.14 & $0.57 \pm 0.02$ \\
\hline L-Glu & 400 & 0.69 & 0.9979 & 0.00 & $0.30 \pm 0.01$ \\
\hline D-Glu & 400 & 0.74 & 0.9956 & 0.08 & $0.26 \pm 0.01$ \\
\hline L-Leu & 384 & 0.98 & 0.9991 & -0.08 & $0.76 \pm 0.01$ \\
\hline D-Leu & 384 & 1.10 & 0.9915 & -0.11 & $0.48 \pm 0.01$ \\
\hline$\beta$-MeAsp, threo, L & 403 & 0.62 & - & - & 工 \\
\hline$\beta$-MeAsp, erythro, $L$ & 403 & 0.68 & - & - & - \\
\hline$\beta$-MeAsp, threo, D & 403 & 0.71 & - & - & - \\
\hline$\beta$-MeAsp, erythro, o & 403 & 0.78 & - & - & - \\
\hline
\end{tabular}

aetention time (RT) of L-Phe is 17:39 min.

- Linear regression analysis. 
hydrolysates over a Chirasil Val capillary column $[1,2$, $6,7]$. The hydrolysates $(0.7-1.0 \mu \mathrm{mol})$ were converted to their corresponding $\mathrm{N}$-trifluoroacetylmethyl esters prior to the GC analysis [6, 7]. In addition, the arginine and homoarginine present in the hydrolysates were converted into their dimethylpyrimidine derivatives of the guanidino group prior to esterification. The isomers were identified based on their retention times over the Chirasil Val column [1, 2, 6, 7]. Detection limits are not specified for any of these experiments, but are presumed to be in the high nanomolar quantities. Detection limits for the FDAA derivatives of amino acids by our LC-thermospray mass spectrometry procedure have been established to be 20 pmol $-3 \mathrm{nmol}$ (Table 1), which is considerably lower than the amount established for GC detection. Although lower amounts might be observed during LC-UV detection of the FDAA derivatives, molecular mass measured during mass spectrometry analysis enabled the unambiguous identification of any specific amino acid isomer. In addition, a single derivatization with FDAA is sufficient for the LC-thermospray mass spectrometry detection of all amino acids, and quantification of the detected isomer is also possible by this procedure.

Thus, the following facts have been definitely demonstrated as a result of our investigations. Derivatization of isomers of amino acids with optically active Marfey's reagent [11] was successful, the adapted derivatizing procedure as stated in the experimental section was simple, and the derivatives resolved well over a simple reverse-phase $\mathrm{C}_{18}$ column. The chromatographic conditions were also amenable to thermospray ionization conditions. The thermospray ionization of the analytes in the LC eluent was also observed to be efficient and reproducible. Our observed sensitivities for investigated isomers were better than previously reported values $[6,7]$. The measured retention times and molecular masses of the FDAA derivatives of the hydrolysates could be utilized for the unambiguous identification of the chiralities of amino acids present in some uncharacterized microcystins. However, optimization of hydrolytic and other experimental conditions is required for the accurate quantification of the isomers.

\section{Acknowledgment}

The author acknowledges the technical assistance provided by Debra Beck of Oneida Research Services, Whitesboro, NY.

\section{References}

1. Botes, D. P.; Viljoen, C. C.; Kruger, H.; Wessels, P. L. Toxicon 1982, 20, 1037-1042.

2. Botes, D. P.; Tuinman, A. A.; Wessels, P. L.; Viljoen, C. C.; Kruger, H.; Williams, D. H.; Santikarn, S.; Smith, R. J.; Hammond, S. J. Chem. Soc., Perkin Trans. 1984, 2311-2318.

3. Krishnamurthy, T.; Szafraniec, L.; Hunt, D. F,; Shabanowitz, J.; Yates, III, J. R.; Haeur, C. R.; Carmichael, W. W.; Skulberg, O.; Codd, G. A.; Missler, S. Proc. Nat. Acad. Sci. USA 1989, 86, 770-774.

4. Gathercole, P. S.; Thiel, P. G. I. Chromatog. 1987, 408, 435-440.

5. Carmichael, W. W. I. Appl. Bact. 1992, 72, 445-459.

6. Sivonen, K.; Namikoshi, M.; Evans, W. E; Fardig, M.; Carmichael, W. W.; Rinehart, K. L. Chem. Res. Toxicol. 1992, 5, 464-469.

7. Namikoshi, M.; Rinehart, K. L.; Saka, R.; Slotts, R. R.; Dahlem, A. M.; Beasley, V. R.; Carmichael, W. W.; Evans, W. R. J. Org. Chem. 1992, 57, 866-872.

8. Rinehart, K. L.; Harada, K. I.; Namikoshi, M.; Chen, C.; Harvis, C. A.; Munro, M. H. G.; Blunt, J., W.; Mulligan, I. E.; Beasley, V. R.; Dahlem, A. M.; Carmichael, W. W. I. Am. Chem. Soc. 1988, 110, 8557-8558.

9. Namikoshi, M.; Rinehart, K. L.; Dahlem, A. M.; Beasley, V. A.; Carmichael, W. W. Tetrahedron Lett. 1989, 30, 4349-4352.

10. Carmichael, W. W.; Krishnamurthy, T.; Beasley, V. A.; MinJuan, Y.; Bunner, D. L.; Moore, J. E.; Eloff, J. N.; Rinehart, K. L.; Falconer, I.; Runnegar, M.; Gorham, P.; Skulberg, O. M.; Harada, K.; Watanabi, M. Toxicon 1988, 26, 971-973.

11. Marfey, P. Carlsberg Res. Commun. 1984, 49, 591-596.

12. Nambara, T. In CRC Handbook of HPLC for the Separation of Amino Acids, Peptides, and Proteins; Hancock, W. S., Ed.; CRC Press: Boca Raton, FL، 1984; Vol. 1, pp. 383-389. 